\title{
ADONIAS FILHO E A BIBLIOTECA NACIONAL NOS ANOS 60
}

\author{
Luciana Grings \\ Fundação Biblioteca Nacional, Rio de Janeiro, Brasil. \\ vanessa.barrozo@ufrgs.br \\ https://orcid.org/0000-0001-7123-0127
}

\section{RESUMO}

Enfoca a gestão de Adonias Filho como diretor da Biblioteca Nacional do Brasil, ocorrida entre os anos de 1961 e 1971. Têm por base as considerações elaboradas na tese de doutorado "O leigo e a especialista", publicada em 2019, e procura trazer à luz mais elementos para compreender o contexto social e a Biblioteca Nacional do Brasil durante os anos 1960. O corpus documental analisado foi composto, majoritariamente, por recortes de jornais da época. Resgata a memória de eventos institucionais e excepcionais, como a CPI da Biblioteca Nacional, ocorrida em 1966, cujo resultado foi inócuo e constata que não houve evolução com relação aos problemas institucionais daquele período.

Palavras-chave: Fundação Biblioteca Nacional. Adonias Filho. Administração de bibliotecas. Bibliotecas nacionais. CPI da Biblioteca Nacional.

\section{ADONIAS FILHO AND THE NATIONAL LIBRARY IN THE 60'S}

\section{ABSTRACT}

This article focuses on the management of Adonias Filho as director of the National Library of Brazil, which took place between the years 1961 and 1971. Based on the considerations elaborated in the doctoral thesis "The layman and the specialist", published in 2019, seeks to bring to light more elements to understand the social context and the National Library of Brazil during the 1960s. The documentary corpus analyzed was composed mainly of newspaper clippings of the time. It rescues the memory of institutional and exceptional events, such as the PCl of the National Library, which occurred in 1966, whose result was innocuous, and notes that there was no evolution regarding the institutional problems of that period.

Keywords: National Library Foundation. Adonias Filho. Library management. National libraries. National Library PCl.

Publicado em: 12/07/2021

\section{INTRODUÇÃO}

Ao concluir a tese de doutorado intitulada $O$ leigo e a especialista: memórias da administração da Biblioteca Nacional nas décadas de 1960 e 1970¹, restou em mim uma grande curiosidade a respeito do interlocutor escolhido para dialogar com Jannice Monte-Mór naquele trabalho. À época, a tese comparou a gestão desta, a primeira bibliotecária a dirigir a Instituição, com a de Adonias Filho, o antecessor, escritor e jornalista. O corpus documental eleito para a pesquisa privilegiou as fontes primárias e documentais, mas delas pouco se soube de efetivo sobre quem era, de fato, Adonias Aguiar Filho: não foram localizados,

\footnotetext{
${ }^{1}$ A tese foi defendida em 2018 no Programa de Pós-graduação em Memória Social da Universidade Federal
} do Estado do Rio de Janeiro e, posteriormente, editada em livro (GRINGS, 2019). 
nos arquivos da Fundação Biblioteca Nacional (FBN), sequer os relatórios de gestão de todos os seus dez anos como diretor.

O período da gestão de Adonias Filho foi pontuado por diversos acontecimentos marcantes do ponto de vista social, político e institucional, tanto para a biblioteconomia quanto para a Biblioteca Nacional (BN) em si. Foi entre 1961 e 1971 que o Brasil viu a ascensão do militarismo ao poder federal através de um golpe de Estado, bem como o recrudescimento desse regime; no início da década, estava candente o debate sobre a transferência das instituições federais do Rio de Janeiro para a recém-inaugurada capital planejada, Brasília; no âmbito biblioteconômico, a profissão de bibliotecário foi, finalmente, regulamentada; para a Biblioteca Nacional, foi um período complicado, de problemas internos e instauração de comissão parlamentar de inquérito (CPI) para investigar suas dificuldades.

Este artigo vem, portanto, como um rizoma deleuze-guattariano (DELEUZE; GUATTARI, 1995), tentar saciar uma curiosidade e também preencher uma lacuna da tese, buscando traçar um retrato mais acurado da figura do diretor da Biblioteca Nacional durante os anos 1960. $\mathrm{Na}$ impossibilidade de retornar à documentação primária (em virtude da pandemia do coronavírus, período de redação e pesquisa), e ampliando as fontes de busca, aqui, os dados foram extraídos, majoritariamente, dos jornais da época, consultados através da Hemeroteca Digital Brasileira da FBN. Cabe comentar que, ao buscar pelo nome do ex-diretor, no acervo da BN Digital, apenas um registro é retornado, e se refere aos Anais da Biblioteca Nacional. A propósito, nenhum dos fascículos dos Anais editados em sua administração traz o expediente institucional, no qual constaria seu nome.

A estratégia de busca na Hemeroteca foi delimitar os periódicos ao período de 1960 a 1969, cobrindo, assim, a maior parte da gestão de Adonias Filho na BN, sem restringir o local de publicação; com isso, a busca foi feita em 248 títulos. Ao procurar, inicialmente, por "Adonias Filho", houve um retorno de 4.078 ocorrências em 70 periódicos; ao estreitar a busca, incluindo na pesquisa o termo "biblioteca nacional", os resultados foram 665 ocorrências em 44 periódicos, sendo apenas treze editados fora do Rio de Janeiro. Os cinco periódicos com mais ocorrências foram, em ordem decrescente: Jornal do Brasil (JB), Correio da Manhã (CM), O Jornal, Jornal do Commercio (JC) e Diário de Notícias (DN). Juntos, eles somaram 444 das ocorrências desta pesquisa.

Uma segunda investigação pareceu pertinente a partir da constatação de que muito pouco do conteúdo já lido abordava a CPI da Biblioteca Nacional, ocorrida em 1966. 


\section{BIIOIOS E-ISSN 2236-7594}

Assim, nova busca pelos termos "cpi" e "biblioteca nacional" foi realizada na Hemeroteca, usando-se o mesmo período como delimitador. Dessa vez, o retorno foi de 187 ocorrências, mas apenas 14 se mostraram pertinentes para os fins desta pesquisa. Vários dos resultados foram recuperados em função de problemas no reconhecimento dos caracteres, que confundiu "cpi" com "cpl" ou, recorrentemente, "upi" - sigla de United Press International, agência de notícias sediada na Inglaterra bastante citada como fonte das matérias de jornal.

Cabe, aqui, esclarecer a que se refere o termo "ocorrência": trata-se da localização dos termos de busca em uma mesma página (de jornal, neste caso), não necessariamente conectados ou relacionados um ao outro no conteúdo em que aparecem. Assim, puderam-se verificar falhas no sistema de reconhecimento dos caracteres: enquanto diversas ocorrências dos termos na mesma página não foram capturadas, onze ocorrências foram duplicadas, ou, por aparecerem em uma mesma página, ou por estarem em páginas escaneadas duplamente. Em quatro casos, o carimbo da BN foi identificado como ocorrência. Quarenta e quatro ocorrências foram retornadas pelo sistema mesmo estando fora do escopo temporal da pesquisa, incluindo notas de falecimento de Adonias (ocorrido em 1990). Exatamente uma centena de ocorrências não trazia correlação entre os termos da pesquisa. Assim, o universo de recortes e matérias pesquisado para este artigo foi de cerca de 500 itens.

Embora a imparcialidade dos periódicos como fontes de informação esteja ainda em disputa (LUCA, 2006), é fundamental entender que, em determinados contextos, é justamente essa imparcialidade a possibilidade da manifestação da imprensa ser mais pessoal e autoral, que permite identificar aquilo que Foucault (2005) denomina regularidades discursivas: marcas e formações do discurso que permitem inseri-lo em determinada ordem, num quadro definido social e historicamente. Espera-se, desse modo, que a análise do corpus aqui proposto possa iluminar regularidades relativas não só a Adonias Filho, mas à BN e à biblioteconomia na década de 1960.

\section{QUEM FOI ADONIAS FILHO}

Embora a obra de Adonias Aguiar Filho venha recolhida a uma espécie de "ostracismo" após seu falecimento, em 1990 (MOTA, 2017), parece indiscutível que a figura do autor baiano seja de extrema importância no quadro dos grandes autores modernistas brasileiros. Carlos Nejar, em sua monumental História da literatura brasileira, pontua: 
Foi romancista e ensaísta. Inovador na ficção brasileira, inventor de criaturas primitivas sujeitas à paixão, à luta e ao tempo. [...] há um injustificado silêncio sobre a ficção extraordinária de Adonias Filho, ele que ajudou inúmeros intelectuais presos na ditadura. E chegou o tempo de reconhecê-lo e amá-lo, desarmando, essa ideologia que tem cometido absurdos entre nós, como o de propor a autênticos criadores outros bem menores esteticamente, protegidos por partido, bandeiras ou sistemas, que nada têm a ver com literatura. (NEJAR, 2011, p.546-547. Grifo no original)

É particularmente interessante essa inserção de matizes ideológicos para falar de Adonias Filho, um "espírito rigorosamente integrado nos propósitos e nas aspirações da revolução democrática [sic] de abril [de 1964]" (O JORNAL, 19 maio 1964, p.4). Nascido em Itajuípe/BA, em 27 de novembro de 1915, e falecido em Ilhéus/BA, em 2 de agosto de 1990, ele imprimiu, em sua produção literária, o entorno familiar: filho e herdeiro de fazendeiros de cacau, fez do ambiente da zona cacaueira baiana o pano de fundo de boa parte de sua escrita. Ao mudar-se para a capital, Rio de Janeiro, aos 21 anos, iniciou uma sequência de empregos nos jornais locais, ingressando, no Correio da Manhã, como colaborador; posteriormente, teria colunas de crítica literária em outros periódicos de grande circulação como O Semanário, Diário de Notícias e $A$ Noite - cuja editora dirigiu de 1946 a 1950. No mesmo ano em que assume a direção da editora, publica seu romance de estreia, Os Servos da Morte. Ao longo da carreira, publicou mais de duas dezenas de obras, entre romances, ensaios, peças de teatro e literatura infantil. Adonias Filho estreou, no serviço público, como diretor do Serviço Nacional de Teatro, em 1954, assumindo a Biblioteca Nacional, em 1961, e a Agência Nacional, órgão de notícias do governo, em 1964.

O escritor nunca escondeu sua afinidade com as bandeiras conservadoras - mesmo que, como disse Nejar, tenha ajudado intelectuais prejudicados pela ditadura militar. Foi candidato a deputado federal pela $U D^{2}$, em 1950, e, em 1974, chegou a ser listado como sucessor de Antônio Carlos Magalhães no governo da Bahia. Amigo de Golbery do Couto e Silva, de Carlos Lacerda e de militares como Siseno Sarmento ${ }^{3}$ - a quem, segundo a Tribuna da Imprensa de Lacerda, vinha prestando assessoria na chefia de Polícia no início de 1961 -, Adonias Filho foi nomeado diretor da Biblioteca Nacional pelo conservador Jânio Quadros, assumindo o posto em 20 de fevereiro de 1961.

2 União Democrática Nacional, partido conservador fundado em 1945 e dissolvido em 1965, sucedido pela Aliança Renovadora Nacional (Arena).

${ }^{3}$ Siseno Sarmento (1907-1983) foi um dos executores do golpe militar de 1964; criou o DOI-Codi, em 1969, e chegou a ser cogitado para assumir a Presidência da República em substituição à junta militar que assumiu o poder depois do afastamento de Costa e Silva. 
Duas semanas antes, o Última Hora publicou que ele teria afirmado a amigos ter sido convidado para assumir o Serviço Nacional de Teatro, mas não teria aceitado; em compensação, estava cotado para assumir a BN o filólogo Artur de Almeida Torres.

Talvez tenha pesado em favor do romancista uma campanha pública que ele mobilizou, em janeiro de 1961, em prol da valorização do bibliotecário servidor público e a favor da regulamentação do nível universitário para a classe (AGUIAR FILHO, 1961). A campanha foi endossada por Antônio Caetano Dias, diretor dos cursos de biblioteconomia da BN e diretor interino da Instituição. Entre julho de 1960 e fevereiro de 1961, revezaram-se, na direção, Celso Cunha - que havia se exonerado - e José Elísio Condé, cuja nomeação desmentiu a notícia publicada pelo Jornal do Commercio, em 5 de maio de 1960, de que Antônio Houaiss assumiria a BN. Curioso é notar que houve muita especulação sobre quem finalmente assumiria a Biblioteca em 1961.

A nomeação de Adonias Filho para a direção da Biblioteca Nacional foi muito bem recebida em todos os círculos, dos intelectuais à imprensa, passando pelos bibliotecários. Houve repercussão até em Portugal: o advogado e jornalista Martinho Nobre de Mello escreveu editorial para o Diário Popular de Lisboa, posteriormente reproduzido no Jornal do Commercio, saudando o colega. A Noite, evidentemente, também publicou nota de parabenização à escolha "das mais felizes", já que se tratava de "um intelectual autêntico". Mauritônio Meira, colunista de cultura do Jornal do Brasil, assegurou que o nome dele era "garantia de uma administração correta e inteligente". A inteligência, o saber e a determinação de Adonias Filho também foram bem acolhidos pela Associação Brasileira de Bibliotecários, que encaminhou correspondência ao escritor saudando-o pela indicação. Sua nomeação e posse renderam-lhe 26 notas na imprensa.

\section{PRIMEIROS ANOS DA GESTÃO: O “DIRETOR DA BIBLIOTECA NACIONAL”}

A gestão de Adonias Filho como diretor da Biblioteca Nacional já iniciou com um fato novo logo na cerimônia de posse: Celso Cunha, o diretor de saída, entregou em suas mãos cópia da declaração de bens da Biblioteca e pediu que fosse anexada ao seu processo de nomeação. O recém-empossado "dobrou a declaração de bens de Celso Cunha e nada disse acerca do pedido feito de público" (A NOITE, 04 mar. 1961, capa). Começou assim a gestão de Adonias Filho, identificado como diretor da Biblioteca Nacional em praticamente todas as publicações recuperadas na pesquisa na Hemeroteca Nacional. Em 85 delas, 
contudo, a fórmula "Adonias Filho, diretor da BN" foi considerada irrelevante de conteúdo sobre seu trabalho na Biblioteca. Eram avisos de que o escritor daria uma palestra, esteve em algum lugar, mandou um cartão de boas festas para um colunista.

Algumas dessas ocorrências chamaram a atenção pela tendência ao colunismo social ou à pura futilidade. Em novembro de 1961, O Jornal tratou de avisar a todos: "Aniversariante de amanhã: o escritor Adonias Filho, diretor da Biblioteca Nacional". Também soubemos pelo mesmo diário, em 23 de dezembro de 1962, das lembranças de infância do escritor: "Adonias Filho (diretor da BN): Papai Noel foi uma realidade até os seis anos. Esperava-o, inquieto, embora sem vê-lo. Sem ele, efetivamente, a infância não teria sido". Em setembro de 1965, o Diário de Notícias deu pistas do rumo que a vida de Adonias Filho tomaria: "Você sabia que... Adonias Filho é diretor da Biblioteca Nacional e da Agência Nacional, além de ser fazendeiro de cacau na Bahia". Entretanto, a mais bizarra das notas, no quesito correlação entre Adonias Filho e a BN, foi dada na Tribuna da Imprensa, em 1966: "Chegou ao fim da linha o romance entre o 'bachelor' Kalouf Djmal e a bonita secretária do escritor Adonias Filho, na Biblioteca Nacional, srta. Fátima Barbosa".

$\mathrm{O}$ ano um da gestão Adonias Filho foi de primeiros contatos com a realidade da biblioteca e, sem dúvida, de certo estranhamento. Sua primeira providência foi a de organizar o serviço estatístico, para o qual pediu um técnico do IBGE; como consequência, ele veio a provar que, apesar das deficiências, a biblioteca funciona ${ }^{4}$. Entretanto, o "chão de fábrica" trouxe-Ihe alguns dissabores: segundo nota de $A$ Noite, publicada em 24 de março de 1961,

o professor Adonias Filho está impressionado com a quantidade de maníacos que frequenta a BN teimando em querer ilustrar-se. E o pior segundo Adonias - é que estes cavalheiros perturbam seriamente a vida da BN e os que vão ali realmente em busca de luzes e saber. (A NOITE, 24 mar. 1961, p.2)

O tema dos frequentadores da biblioteca foi objeto de matéria de Coutinho (1961, p.3), em que volta a chamar a atenção o uso do termo "maníacos" para descrever aqueles que adentram a BN não para pesquisar, mas para distrair-se. E Adonias Filho dá ao jornalista uma declaração (bastante infeliz), lamentando que a frequência de pesquisadores "sérios" seja prejudicada pela presença de pessoas que perturbam o ambiente: "doentes mentais sentem grande atenção pelo manuseio de livros". Posteriormente ele passaria a adotar o discurso (endossado pela teoria biblioteconômica)

${ }^{4}$ Declaração dada à CPI da Biblioteca Nacional em 1966. 
de que não compete à Biblioteca Nacional o atendimento de leitores em geral ${ }^{5}$, sendo seu papel o de instituição patrimonial, de memória e de consulta de última instância, admitindo que atender ao público que deveria estar frequentando as bibliotecas públicas "atravanca" as atividades próprias da BN (CAMPOS; CONTREIRAS; 1968, p.10).

Pouco tempo depois, começa a luta pelas duas bandeiras marcantes de seu discurso: a autonomia administrativa da Instituição e a reivindicação de mais espaço para as coleções. O Jornal do Commercio pontuou, já em abril de 1961, os problemas de falta de espaço, lembrou que a BN poderia ser "assistida pelo Estado" quando a Biblioteca Nacional de Brasília fosse criada e apelou à Light para que propiciasse a ligação do ar condicionado e do setor de microfilmagem. Em junho, o Correio Braziliense soma suas informações à matéria de Coutinho de $O$ Jornal e divulga que Adonias Filho entrará em contato com o governador do Estado, o amigo Carlos Lacerda, para pedir a cessão de uma área na Glória para a construção de uma biblioteca pública, o que desafogaria o atendimento da BN. O Diário de Notícias, na mesma semana, publica sobre uma "reorganização geral da Biblioteca Nacional", que seria estudada por uma comissão especial recém-constituída pelo Ministério da Educação e Cultura; o objetivo seria "estabelecer as bases para a BN adquirir autonomia administrativa" (DIÁRIO..., 03 jun. 1961, p.4).

Ainda em 1961, estabeleceu-se, publicamente, o plano de gestão de Adonias Filho: a Biblioteca seria um potente centro e difusor de exposições, lutaria pela expansão de seu espaço, preferencialmente através da aquisição de um prédio anexo, e se inseriria no conceito de "biblioteca moderna", a despeito da falta de pessoal para executar esses intentos. O jornalista Miranda Neto tratou de trazer à luz de seus leitores esse plano e o apelo do jornal:

O velho e o novo Jornal do Commercio unem agora o seu apelo: é necessário que o público conheça o que é a $\mathrm{BN}$, é necessário que o governo compreenda que o investimento feito em uma Biblioteca Nacional é investimento a longo prazo, que paga dividendos em cultura, ao revés de certos investimentos demagógicos, que dão logo bons e fartos lucros em voto e prestígio. (MIRANDA NETO, 1961, p.1)

\footnotetext{
${ }^{5}$ Muito sucintamente, o papel de uma biblioteca nacional, sendo beneficiária da legislação de depósito legal, é o de reunir e preservar a produção bibliográfica de um país. Para atender a diferentes necessidades de leitura e de informação das comunidades, existem diferentes tipos de bibliotecas: públicas, comunitárias, universitárias, escolares, especializadas. Um sistema bibliotecário adequado e consolidado permitiria a cada uma delas exercer seu papel sem onerar as demais; é nesse sentido a fala de Adonias Filho. Sobre o conceito de biblioteca nacional, ver GRINGS, 2019. Sobre bibliotecas públicas, um documento essencial é o Manifesto da IFLA/Unesco sobre bibliotecas públicas, de 1994 (disponível em https://www.ifla.org/files/assets/publiclibraries/publications/PL-manifesto/pl-manifesto-pt.pdf. Acesso em 5 out. 2020).
} 


\section{BILIOSE E-ISSN 2236-7594}

De fato, são as exposições e eventos da Biblioteca Nacional, no país ou no exterior, os responsáveis por 136 das ocorrências encontradas na pesquisa, demonstrando que o plano de Adonias Filho foi cumprido no que se referia à dinamização da biblioteca enquanto centro cultural. Merece destaque a atuação da chefe da Seção de Música, Mercedes Reis Pequeno, cuja produção de exposições rendeu notas, em geral, mais extensas e profundas do que o padrão, em que destacavam seu bom gosto e competência. Há também diversas notas a respeito de lançamentos de obras ou recebimento e doação de coleções de livros - inclusive para os jornalistas, que, à época, recebiam material para resenhar em suas colunas. Os eventos divulgados foram os mais diversos: anotou-se a presença de Adonias Filho em colações de grau de biblioteconomia, seminários, aberturas de exposições, palestras, entregas solenes de obras, inaugurações de monumentos.

Conforme comenta Carvalho (1994), não foram publicados relatórios de gestão da Biblioteca Nacional entre 1944 e 1971, o que não impediria, entretanto, que esses documentos estivessem armazenados na própria Biblioteca. Contudo, quando da pesquisa para a tese (GRINGS, 2019), não identifiquei, nos arquivos da Instituição, os relatórios de gestão dos quatro primeiros anos da gestão de Adonias Filho. É curioso que não haja cópia desses documentos, já que, em março de 1962, o Diário Carioca, o Diário de Notícias e o Jornal do Commercio trataram de informar ao grande público que o diretor havia encaminhado o relatório de atividades da BN ao MEC, inclusive apresentando breve resumo estatístico. Também foi publicado, na ocasião, que novo regimento estava sendo redigido para a Biblioteca e que o plano de reforma dos cursos da Biblioteca já tinha sido aprovado pelo ministro.

Em dezembro de 1962 a Biblioteca Nacional ganhou uma extensa matéria, ricamente ilustrada, na revista Manchete. Assinada pelo jornalista e acadêmico R. Magalhães Júnior, em tom impessoal, $O$ silencioso mundo da cultura chamou a atenção para o grande fluxo de estudantes que frequentava a Instituição, trazia curiosidades dos leitores assíduos e apontava a falta de espaço. O nome de Adonias Filho só aparece no último parágrafo da matéria, acompanhado de observação que insinua o caráter político ${ }^{6}$ do cargo de direção da BN:

\footnotetext{
${ }^{6}$ Alguns anos depois, quando da substituição de Adonias Filho por Jannice Monte-Mór, Rubens Borba de Moraes chamaria o cargo de diretor da Biblioteca Nacional de "sinecura para literatos" e "antecâmara ou sucursal do salão de chá da Academia Brasileira” (ACUSAÇÃO..., 1971, p.7)
} 
Quase sempre dirigida por escritores, ali passaram, entre outros, Ramiz Galvão, Teixeira de Melo, Constâncio Alves, Rodolfo Garcia, Eugênio Gomes, Josué Montello e, finalmente, Adonias Filho, que é o atual diretor e que tem, ao seu redor, valores como Paulo Mendes Campos, na Divisão de Obras Raras, Caetano Dias, na direção do curso de biblioteconomia, além de vários outros, igualmente interessados no prestígio da instituição que D. João VI criou. (MAGALHÃES JÚNIOR, 1962, p.97)

Naquele ano, já estava consolidada a permanência da BN no Rio de Janeiro, mas não propriamente por esforço institucional: o Correio da Manhã notou a "falta de protesto enérgico da parte mais ameaçada" ao finalmente ser oficializada a comissão para criar a Biblioteca Nacional em Brasília7 (21 maio 1962, p.6). Adonias Filho declarou ao Diário Carioca que a biblioteca de Brasília "vai demorar, porque o prédio nem começou a ser construído ainda e nem se sabe se existe uma planta para as obras, ou prazo para executá-las" (DIÁRIO..., 4 maio 1962, p.1). Com efeito, o plano piloto da capital federal planejada não incluiu espaço para a BN: "o genial Lúcio Costa confessou-me que esqueceu por completo as bibliotecas", disse Edson Nery da Fonseca (CHAVES, 2009). Seria mais justo dizer que a Biblioteca Nacional permaneceu no Rio por força de campanha pública, já que, no dizer do frequentador Carlos Drummond de Andrade, "a BN é um pouco a alma do Rio" (1960, p.6); ou, como pontuou a bibliotecária Lydia de Queiroz Sambaquy, "a Biblioteca Nacional do Rio de Janeiro deve ser intocável" (BRASIL, 1966, p.429). De fato, a confusão burocrática para transferir uma instituição do porte da BN também deve ter pesado substancialmente para sua manutenção na cidade de origem.

Segundo Carpeaux (1962), a promessa do presidente foi a de manter a BN no Rio de Janeiro, assim como as demais grandes instituições culturais. $O$ autor não via motivos para gratidão pelo cumprimento da promessa, mas manifestou preocupação com o custo e as condições de criação de uma segunda BN:

O projeto fala em aliviar a BN do Rio de Janeiro pela transferência das duplicatas. Mas não se trata de aliviá-la e, sim, de enchê-la de livros. [...] Muito dinheiro será preciso para lançar os fundamentos de uma muito modesta BN II em Brasília. Quanto dinheiro restará para a BN I no Rio? $A$ verdadeira Biblioteca Nacional estaria condenada à morte lenta, para que viva precariamente uma outra, longe dos centros da civilização brasileira.

O tema não se esgotou de imediato. Por ocasião dos estudos para reforma administrativa do Ministério da Educação, em 1968, ainda se ventilava a ideia de transferir

\footnotetext{
7 Através do Decreto do Conselho de Ministros n.927-A, de 27 de abril de 1962, assinado por Tancredo
} Neves. Atualmente, a biblioteca chama-se Biblioteca Distrital Leonel de Moura Brizola. 
a Biblioteca Nacional para Brasília. Enquanto todas as repartições centrais do MEC seriam transferidas, a BN continuaria no Rio; Celso Kelly, membro do grupo de trabalho da reforma, declarou que ela ficaria "aqui mesmo, por não poderíamos transferir a instituição para a Capital, que possui uma biblioteca cujo acervo já é bastante significativo" (SERVIÇOS..., 1968, p.10).

Nesse ínterim, um passo importante para a classe bibliotecária foi dado: em 30 de junho de 1962, foi promulgada a Lei 4.084, que dispõe sobre o exercício da profissão de bibliotecário. $O$ detalhe importante foi a prescrição, no artigo $6^{\circ}$ da lei, de que a administração e a direção de bibliotecas era atribuição dos bacharéis em biblioteconomia. Essa redação mobilizou a classe bibliotecária e gerou polêmica. Embora reconhecesse que não era possível aplicar a regra retroativamente, o combativo Edson Nery da Fonseca (1963, p.1) tratou de elogiar a legislação e alfinetar os escritores que dirigiam bibliotecas, sugerindo "que façam o curso de Biblioteconomia. Não queiram ocupar cargos sem assumir os respectivos encargos".

Os jornais também repercutiram a necessidade da formação em biblioteconomia para assumir a direção das bibliotecas, publicando especulações sobre uma substituição de Adonias Filho na Biblioteca Nacional. Em 9 de julho de 1963, o Última Hora informou que

O Sr. Aurélio Buarque de Holanda está tentando ser nomeado para a direção-geral da BN, tendo como "padrinho", junto ao Ministro Paulo de Tarso, o Senador Arnon de Melo. Há uma dificuldade para Aurélio ser atendido. É que saindo Adonias Filho, o novo diretor terá que ser bibliotecário e Aurélio não é.

O ano de 1963 terminou com a Biblioteca Nacional estampando as páginas dos jornais em virtude do pleito dos estudantes leitores pela ampliação do horário de atendimento na Instituição - e dos banheiros disponíveis. O Correio da Manhã, de 15 de novembro, publicou: "Biblioteca poderá fechar só às $24 h$ ". Na matéria, os estudantes reclamam que o horário não era favorável, o espaço, insuficiente, e as instalações sanitárias, precárias. Adonias Filho informou que já havia pedido verba para resolver o problema, mas não tinha recebido resposta. Quatro dias depois, o mesmo jornal publica nota dizendo que a "Biblioteca Nacional vai até 23h: O diretor da BN, escritor AF, atendendo a apelo de estudantes, deliberou que, a partir de hoje, a biblioteca funcionará no horário das 9h30min às 23h ininterruptamente" (CORREIO..., 19 nov. 1963, p.12). A queixa se devia principalmente à dificuldade de encontrar mesas disponíveis para estudar, já que os salões de leitura, segundo os frequentadores, estavam sempre lotados. 


\section{BIIOIOS E-ISSN 2236-7594}

O debate foi estendido e durou mais de um ano. Em 21 de novembro de 1963, leitor do Correio escreveu comentando que, de fato, as mesas de leitura estavam sempre ocupadas por jovens "fazendo os seus deveres". O redator do jornal completou: "Talvez os estudantes procurem na Biblioteca a tranquilidade que não existe nem mesmo nos salões de seus estabelecimentos. O problema é menos do sr. Adonias Filho do que das famílias, das faculdades e dos colégios." O horário ampliado durou até janeiro de 1965. Em 31 de dezembro de 1964, o mesmo Correio da Manhã deu o serviço:

Modificado horário na Biblioteca: A fim de melhor atender aos trabalhos de reorganização do setor de armazenamento de livros e outros serviços correlatos, determinou o diretor da $\mathrm{BN}$, escritor $\mathrm{AF}$, que o horário para o público da seção de leitura seja encerrado às 18 horas, no mês de janeiro próximo. (CORREIO..., 31 dez. 1964, p.3)

Ainda em 1963, a questão dos elevadores monta-cargas da Biblioteca Nacional também mereceu diversas pautas, embora não fosse um problema novo. No final de 1960, Antônio Caetano Dias, o diretor interino, explicou a O Jornal que "é realmente caso de polícia o abandono dos serviços de instalação dos novos elevadores da Biblioteca Nacional, pela firma que ganhou a concorrência..." (22 dez. 1960). Três anos depois, o Jornal do Brasil publicou que os consulentes estavam "comemorando" três anos sem elevadores que estavam parados desde a gestão de Celso Cunha, e que Adonias Filho informou que seria impossível instalar os monta-cargas de periódicos antes de 1964, já que tinha ocorrido corte de verbas. Em março de 1965, o Correio da Manhã noticiou a assinatura de novo contrato de instalação dos equipamentos; os elevadores, contudo, só foram instalados em 1968.

No início de 1964, entretanto, a resolução de uma situação que prejudicava o atendimento do público especializado da BN ganhou contornos policialescos na redação jornalística. Em 30 de janeiro daquele ano, $O$ Jornal trouxe a tendenciosa nota "Arrombadores ganharam 30 mil do MEC para abrirem um velho cofre da BN". Melhor serviço fez o Jornal do Brasil, informando que "Cofre de chave quebrada que guarda gravuras de Debret vai ser arrombado". O que ocorreu é que a fechadura de um velho cofre da Seção de Iconografia estava quebrada há cerca de dois meses e o atendimento dos consulentes da seção estava se atrasando. Liberada a verba pelo MEC para a abertura do cofre, foram chamados os especialistas, e o caso solucionado - mais uma mostra da morosidade na resolução de problemas causada pela falta de autonomia administrativa. 
Como já sabemos, no entanto, o grande marco político e social do período da gestão de Adonias Filho foi o golpe civil-militar de 31 de março de 1964, quando o presidente democraticamente eleito João Goulart teve o mandato cassado e foi buscar exílio no Uruguai. Para a Biblioteca, as implicações diretas não foram muitas. Como de costume nas transições de gestão, houve especulações sobre o destino de Adonias Filho no novo regime. Pouco antes do golpe, em 3 de março, o colunista do Última Hora José Mauro que "detestava a vida mundana", segundo Luís Nassif (2005), destilou:

Embora se trate de pessoa íntegra, intelectual, sério, a verdade é que o Sr. Adonias Filho sempre comungou com os ideais da reação. É amigo de Carlos Lacerda, foi do grupo do General Canrobert Pereira da Costa e hoje está ligado, no setor militar, a Sizeno Sarmento [sic]. Inimigo declarado do Presidente João Goulart, mesmo assim é o diretor da Biblioteca Nacional. Já esteve para ser substituído por um outro lanterneiro e de menor categoria intelectual e profissional que é o sr. Aurélio Buarque de Holanda. Felizmente, Adonias foi mantido, pois a outra solução seria muito pior para a Biblioteca.

Já em 24 de junho, o colunista divulgou a hipótese de Adonias Filho ocupar o próprio Ministério da Educação - opinião compartilhada pela Tribuna da Imprensa:

\begin{abstract}
Aumentam os rumores da substituição do ministro Flávio Suplicy de Lacerda na pasta da Educação. Seria substituído pelo escritor Adonias Filho, que foi quem planificou - por incumbência do Palácio do Planalto a criação do Ministério da Cultura. Sua ida para a Educação, aliás, faria parte do esquema do desmembramento, já que o Ministério da Cultura sairia do da Educação. No momento, Adonias, além da direção da BN, dirige um posto-chave para o governo federal que é a Agência Nacional ${ }^{8}$, em fase mais atuante.
\end{abstract}

O acúmulo da direção de dois órgãos do governo federal - Biblioteca Nacional e Agência Nacional -, enquanto ainda mantinha prolífica produção literária, trouxe a Adonias Filho certa desconfiança da opinião pública. Na revista O Cruzeiro, de 31 de outubro de 1964, o colunista José de Anchieta pontuou: "O escritor Adonias Filho, Diretor da Agência Nacional e da Biblioteca Nacional, resolve seu problema [de tempo] da seguinte maneira: escreve na Agência Nacional e lê na Biblioteca. É claro" (p.117).

\footnotetext{
${ }^{8}$ A Agência Nacional (AN) era o órgão oficial de notícias do governo federal. Adonias Filho foi nomeado para a direção da NA, cargo que acumulou com a direção da BN, em 13 de maio de 1964.
} 


\section{BIIOIOS E-ISSN 2236-7594}

\section{O “ACADÊMICO”}

Em setembro de 1964, falece o acadêmico gaúcho Álvaro Moreyra, depois de apenas cinco anos como ocupante da cadeira n. 21 da Academia Brasileira de Letras ( $A B L)$. Começa, então, um curto período de especulações públicas em torno da eleição de seu sucessor. No páreo, estão o filólogo Antenor Nascentes e Adonias Filho. A candidatura, eleição e posse do escritor na Academia Brasileira de Letras foram motivo de 23 manifestações nos jornais. Adonias Filho foi eleito em 14 de janeiro de 1965, com 49 anos; obteve 24 votos, enquanto o concorrente obteve oito. Nem a sua eleição, aparentemente irretocável, escapou dos comentários nos jornais. Nestor Holanda, do Diário de Notícias, era um dos colunistas francamente favoráveis à eleição de Antenor Nascentes, pela importância de seu trabalho como filólogo e organizador do dicionário da ABL; não só isso, julgava que a eleição de Adonias Filho seria um ato político e, inclusive, de desrespeito para com o escritor baiano. Para ele, Adonias

não merecia [...] o achincalhe acadêmico de haver sido rejeitado quando não tinha posição política, e, agora, porque é diretor da Agência Nacional e da Biblioteca Nacional, e porque tem influência nas hostes governamentais, ser eleito em detrimento da própria obra. (HOLANDA, 1965, p.1)

A partir daí, uma "virada" se deu nos enunciados dos jornais: Adonias Filho deixou de ser somente o "diretor da Biblioteca Nacional" para virar "o acadêmico", modo pelo qual é mencionado inclusive em matéria sobre o lançamento do livro $A$ biblioteconomia brasileira, de Laura Russo, cuja cerimônia aconteceu na própria BN. Eventualmente, percebe-se, também, um aumento na falta de correlação das ocorrências de "adonias filho" e "biblioteca nacional" na mesma página. Grande parte dos resultados obtidos nos jornais da época se deveu à menção da Biblioteca Nacional, na seção O que há para ver, do Jornal do Brasil, que publicava, diariamente, uma lista de opções de lazer, filmes em cartaz nos cinemas, peças de teatro, exposições, programas de rádio e até restaurantes, passando por bibliotecas e museus.

O início de 1965 foi agitado para Adonias Filho. Além da eleição para "imortal" da $\mathrm{ABL}$, ele tomou a importante decisão de retirar as mesas de leitura coletivas da $\mathrm{BN}$ e exigir que os leitores fossem identificados ao ingressar nas salas de leitura e solicitar material para consulta. O objetivo, segundo o Correio da Manhã, de 28 de janeiro, foi o de coibir a presença de "desequilibrados" e acabar com os abusos dos frequentadores 
que usavam as mesas como balcão de negócios, escritório particular ou sala de aula, além do "extravio de livros ou páginas de volumes, havendo casos de exemplares dos quais só ficaram as capas" (BIBLIOTECA..., 1965, p.7). A nota também noticiava que não havia elevadores para 0 trânsito de funcionários entre o $5^{\circ}$ e $\circ$ 6ํadar dos armazéns, e que eram feitas, em média, 600 viagens por dia para atendimento dos leitores.

Em 1966, começam a aparecer os indícios de que Adonias Filho está cansado da vida pública. Lausimar Laus, em coluna no Diário de Notícias, informa que o "diretor da BN e dono de uma fazenda de cacau em Ilhéus, Bahia, acha que no momento já poderia deixar todas as outras ocupações e dedicar-se inteiramente à atividade literária" (LAUS, 1966, p.6). Posteriormente, ele diria que "várias vezes estive a ponto de pedir minha demissão do cargo que ocupo na Biblioteca Nacional; talvez o faça dentro de muito pouco tempo" (BRASIL, 1967, p.330). Ao mesmo tempo, a publicação de um manifesto de Edson Nery da Fonseca, intitulado Ser ou não ser bibliotecário, que tacha a Biblioteca Nacional de "vergonha" causa celeuma e desconforto, não só na classe bibliotecária, mas em todos os "homens de cultura". O acadêmico Afrânio Coutinho aproveitou de espaço disponibilizado pelo Diário de Notícias, em 19 de junho de 1966, e replicou: "A Biblioteca Nacional não é uma vergonha, mas sim um orgulho nacional." Na ocasião, já era público que a Câmara dos Deputados estava montando uma comissão parlamentar de inquérito (CPI) para investigar as condições em que se encontrava a BN. Coutinho conclamou "que se unam os que dela têm auferido lucros culturais de qualquer sorte para pôr em relevo a grandeza daquela instituição" (COUTINHO, 1966, p.4). Concordou que havia deficiências na Instituição, mas pontuou que

o inquédito [sic] deveria ser dirigido para apurar os responsáveis pelo abandono em que a notável instituição foi largada pelos governos. A politicalha e o desperdício de dinheiro em obras desnecessárias é que deviam ser incriminados antes de tudo por essa e outras situações deploráveis [...] a despeito do esforço e da insistência no pedir da parte de seus sucessivos diretores, como é fácil comprovar nos seus relatórios.

Criada a comissão através da Resolução n. 200, de 1966, ela teve sua primeira sessão em 28 de junho daquele ano. Adonias Filho foi o primeiro a depor ${ }^{10}$, na terceira reunião da CPI, em 17 de agosto - depois de cancelamento da reunião do dia anterior

\footnotetext{
${ }_{9}^{9}$ Mais tarde, no mesmo depoimento, ele viria a admitir que começou a pensar em exonerar-se cerca de um ano depois de assumir o cargo.

10 Para fins deste artigo, focarei somente no depoimento de Adonias Filho. Um comentário geral sobre a CPI está em GRINGS, 2019.
} 
por falta de quórum. Além do depoimento, transcrito em 37 páginas, Adonias Filho apresentou aos parlamentares extensa documentação sobre o acervo e o funcionamento da BN (que contava, até 31 de dezembro de 1965, com 3.058.905 peças identificadas), as obras necessárias, no edifício, os catálogos das exposições mais recentes e cópias de correspondências trocadas com instituições do exterior.

Estão nos documentos apresentados os problemas por demais conhecidos de verba, de pessoal (naquele momento a BN tinha 270 funcionários ${ }^{11}$, "por demais deficiente"), o estado precário das dependências do prédio e as poucas providências tomadas pela Divisão de Obras do MEC, responsável pela manutenção de todo o patrimônio do ministério: "estamos até com um aviso de 'risco de vida' naquelas paredes que dão para a Avenida Rio Branco". Estavam na fila para atendimento a montagem dos elevadores e monta-cargas, a impermeabilização do terraço e dos telhados, que já permitiam a infiltração de goteiras, a restauração da fachada, a instalação de rede de telefonia e alarme contra incêndio, a ligação do painel de controle da Light (o que impedia a instalação de sistema de ar condicionado, já que a voltagem da cidade havia sido trocada há pouco), a reforma geral das instalações sanitárias, a construção de uma cisterna e a montagem de forno para incineração de lixo. Foram descritos, em ofício de outubro de 1965, os problemas crônicos de falta de água, da suspensão da instalação dos elevadores, da paralisia causada pela falta de autonomia administrativa, da falta de rede interna de telefonia desde 1962.

Tratou o diretor de incluir, no calhamaço de mais de 200 páginas de documentação, a "cantilena de rotina": relatórios dos chefes de seção apontando os principais problemas de cada uma (recorrentemente, falta de espaço, de pessoal, problemas de equipamentos e goteiras) e os pedidos para atualização da legislação de depósito legal, vigente desde $1907^{12}$. No depoimento, salientou os problemas materiais e a falta de autonomia administrativa, que ele considera a causa mais grave da situação em que a Biblioteca se encontra. Apontou que a gestão dos órgãos, no Rio de Janeiro, foi muito dificultada depois da mudança da capital para Brasília e discorreu, longamente, citando exemplos, sobre como a já citada falta de autonomia embaraçava toda e qualquer providência a ser tomada para resolver os problemas, principalmente físicos e materiais, da Biblioteca.

11 Incluindo carreiras que, hoje em dia, foram extintas ou são passíveis de terceirização, como serviços de segurança, manutenção e limpeza: chefe e auxiliar de portaria, ascensorista, guarda, mensageiro.

12 Na época, Decreto n.1.825, de 20 de dezembro de 1907. 
Chegou a citar casos específicos de demandas solicitadas ao Ministério há mais de cinco anos, sem atendimento.

Em resumo, Adonias Filho insistiu que os problemas mais graves da BN eram, como já sabemos, a "tríade da falta": pessoal (apontou que o quadro de pessoal tinha apenas $50 \%$ da ocupação necessária), espaço (não só a falta de espaço para armazenagem, mas os riscos prementes causados pela falta de água constante, a instabilidade da rede elétrica, a falta de extintores de incêndio) e verba (agravada, sensivelmente, pela falta de autonomia administrativa). Apontou que a situação crítica não afligia só a Biblioteca Nacional, mas todas as instituições de cultura. $\mathrm{Na}$ interpretação do deputado José Bonifácio, Adonias "respondeu a tudo que nos interessava saber sobre o assunto, aliás, com muita franqueza, com muito desassombro e muita coragem" (BRASIL, 1967, p.349).

$\mathrm{Na}$ imprensa, as condições da $\mathrm{BN}$, explicitadas nos depoimentos à $\mathrm{CPI}$, estavam estampadas com a mesma franqueza. O Correio da Manhã, de 19 de agosto, decretou: Biblioteca sem condições de atender leitor. Um mês depois, em entrevista com Marcello de Ipanema, acreditava que Hemeroteca é a solução para a BN. Em dezembro, informou que $C P I$ vê biblioteca sob graves riscos ao seu patrimônio. O Jornal do Brasil também alertou: Biblioteca Nacional está com seu acervo ameaçado por insetos, água e fogo. Nada disso, entretanto, foi suficiente. Tudo o que foi dito já era, como se vê, amplamente documentado e de conhecimento público. Em maio, quando da criação da Comissão, o Jornal do Commercio já dizia:

Essa situação é por demais conhecida. Ao que parece, apenas o Deputado que pediu a criação dessa CPI é que ignora tais fatos, e propõe uma medida sobre todos os títulos inócua, pois ela significa mais o desconhecimento de uma situação que muitos conhecem do que o real desejo de melhorá-la. Esses problemas [...] constam de relatórios de seus sucessivos Diretores que, talvez, nem tenham sido lidos pelos Ministros da Educação e Cultura aos quais foram encaminhados. (A CPI... 1966, p.4)

Ainda durante a $\mathrm{CPI}$, correu o boato de que Adonias Filho teria se demitido. O Jornal disse que o escritor

não quer ser ele declarado responsável pela completa ruína do prédio da Biblioteca, cujo precário estado de conservação ameaça seriamente o patrimônio ali guardado. Cansou-se de apelar para a Administração Geral do Ministério da Educação e Cultura, sem êxito. (17 set. 1966, p.4)

Sua gestão, contudo, perdurou até maio de 1971, quando foi substituído pela primeira bibliotecária a dirigir titularmente a Biblioteca Nacional, Jannice Monte-Mór. 
Nos jornais, entretanto, percebe-se uma paulatina diminuição da frequência de seu nome mencionado em conjunto com o nome da biblioteca. Nesse meio-tempo, em 1967, o escritor ainda foi nomeado para compor o recém-criado Conselho Federal de Cultura, presidido pelo amigo e também ex-diretor da BN Josué Montello. Um de seus pleitos, o de verba para reformas, foi amplamente acolhido pelo Conselho; o apoio para a construção de novo prédio, contudo, foi infrutífero.

Em 1968, na escalada de recrudescimento do regime militar, suas reclamações sobre a truculência da polícia na repressão aos manifestos dos estudantes também repercutiram nos jornais: a BN foi atingida por bombas de gás em julho daquele ano e o diretor foi questionar o motivo do disparo; segundo Barbosa Lima Sobrinho, "o soldado estava apenas interpretando o gosto de perseguir e de castigar, que era evidente em toda a sua tropa" (LIMA SOBRINHO, 1968, p.1). Adonias Filho também se queixou de danos ao prédio da Biblioteca causados pelas bombas lançadas contra o Museu Nacional de Belas Artes naquele ano, que não tiveram repercussão. Parecia, afinal, que o humanista diretor da BN não estava plenamente de acordo com as atitudes do regime que apoiava. Depois de deixar a biblioteca, recolheu-se para suas fazendas de cacau.

\section{5 ÚLTIMAS OBSERVAÇÕES}

É evidentemente impossível esgotar, em um artigo, mesmo que complementar a uma tese, os temas aqui abordados. A riqueza de detalhes cotidianos que emerge da leitura de tanto material permitiria uma multitude de interpretações e narrativas. Chama a atenção, contudo, a enorme quantidade de vezes em que a Biblioteca Nacional apareceu nos jornais da época e a frequência com que o título de diretor da BN foi usado em conjunto com o nome de Adonias Filho. Podemos deduzir que isso se deva ao espaço que o escritor, experiente articulista, já tinha na imprensa e, é claro, acabou usando-o em seu favor e a favor da Biblioteca, mesmo que inconscientemente. De modo enviesado e involuntário, pode-se dizer que Adonias Filho acabou sendo um "homem-sanduíche" (SÜSSEKIND, 1987) da Biblioteca Nacional. Nem toda essa propaganda, como vemos, foi suficiente para que as "pobrezas infinitas" (Correio da Manhã, 19 ago. 1966, p.2) da BN sensibilizassem o Executivo e a opinião pública para a preservação da Instituição.

As grandes questões levantadas por Adonias, e, antes dele, por todos os diretores, permanecem insolúveis até os dias de hoje. O sonhado prédio anexo para a Biblioteca 
foi adquirido na década de 80 , mas já é insuficiente para o acervo que bate com a previsão do escritor: em 1968, com base nos dados de bibliotecas mundiais, ele previu que a BN brasileira alcançaria 8,8 milhões de volumes - número bastante próximo do atual (CAMPOS; CONTREIRAS, 1968). O quadro de pessoal tem, atualmente, apenas 12 pessoas a mais do que em 1965, contando com 282 servidores efetivos (FUNDAÇÃO..., 2019) e com um déficit de mais de 200 postos de trabalho vacantes sem incluir as atividades passíveis de terceirização.

A autonomia administrativa está cada vez mais longe de ser alcançada. Embora tenha o status de autarquia, a Fundação Biblioteca Nacional está, atualmente, vinculada ao Ministério do Turismo e supervisionada pela Secretaria Especial de Cultura - sem, entretanto, ter subordinação direta a esse órgão. Essa "supervisão" exige que não só a Biblioteca, mas todas as entidades vinculadas submetam todas as suas publicações de editais e nomeações a posts em redes sociais - ao crivo do Secretário Especial de Cultura (GOBBI; CALAZANS, 2020). Talvez esses movimentos venham para nos propor uma reflexão: a história está se repetindo ou, na verdade, ainda não evoluímos do quadro que tanto divulgou Adonias Filho em seu tempo?

\section{REFERÊNCIAS}

ACUSAÇÃO à Biblioteca é reafirmada. Jornal do Brasil: segundo caderno, Rio de Janeiro, 14/15 fev. 1971, p.7.

AGUIAR FILHO, Adonias. Não pode continuar. Diário de Notícias: segunda seção, Rio de Janeiro, 14 jan. 1961, p.3.

ANCHIETA, José de. Cochichos. O Cruzeiro, Rio de Janeiro, n.4, 31 out. 1964, p.117.

ANDRADE, Carlos Drummond de. A nossa BN. Correio da Manhã, Rio de Janeiro, 26 jan. 1960, p.6. BIBLIOTECA: diretor põe fim a abusos. Correio da Manhã, Rio de Janeiro, 28 jan. 1965, p.7.

BIBLIOTECA Nacional está com seu acervo ameaçado por insetos, água e fogo. Jornal do Brasil, Rio de Janeiro, 3 dez. 1966, p.5.

BIBLIOTECA sem condições de atender leitor. Correio da Manhã, Rio de Janeiro, 19 ago. 1966, p.2. BRASIL. Câmara dos Deputados. Autos da CPI da Biblioteca Nacional. [Brasília, DF: 1967. Datiloscrito cedido pelo Arquivo da Câmara dos Deputados.

CAMPOS, Fernanda; CONTREIRAS, Hélio. Biblioteca vai ter nova instalação. Correio da Manhã, Rio de Janeiro, 03 fev. 1968, p.10.

CARPEAUX, Otto Maria. Biblioteca Nacional, I e II. Correio da Manhã, Rio de Janeiro, p.2, 11 maio 1962.

CARVALHO, Gilberto Vilar de. Biografia da Biblioteca Nacional (1807 a 1990). Rio de Janeiro: Irradiação Cultural, 1994. 
CHAVES, Teresa. Polêmica e biblioteconomia espelham obra de Edson Nery da Fonseca. Folha Online, São Paulo, 29 jun. 2009. Disponível em:

http://www1.folha.uol.com.br/ilustrada/2009/06/586942-polemica-e-biblioteconomia-espelhamobra-de-edson-nery-da-fonseca.shtml. Acesso em: 22 jul. 2016.

CORREIO da Manhã. Rio de Janeiro: 1901-1974.

COUTINHO, Afrânio. É a Biblioteca Nacional uma vergonha nacional? Diário de Notícias: suplemento literário, Rio de Janeiro, 19 jun. 1966, p.4.

COUTINHO, Edilberto. Maníacos afugentam pesquisadores da Biblioteca: vai ser reformada. O Jornal, Rio de Janeiro, 4 jun. 1961, p.3/9.

A CPI da Biblioteca. Jornal do Commercio, Rio de Janeiro, 28 maio 1966, p.4.

CPI vê biblioteca sob graves riscos ao seu patrimônio. Correio da Manhã, Rio de Janeiro, 3 dez. 1966, p.2.

DELEUZE, Gilles; GUATTARI, Felix. Mil platôs: capitalismo e esquizofrenia v.1. Rio de Janeiro: Ed.34, 1995.

DIÁRIO Carioca. Rio de Janeiro, 1928-1965.

DIÁRIO de Notícias. Rio de Janeiro: 1930-1976.

FONSECA, Edson Nery da. O criminoso volta ao lugar do crime. Diário de Notícias: suplemento literário, Rio de Janeiro, 31 jan. 1963, p.1.

FOUCAULT, Michel. A arqueologia do saber. 7.ed. Rio de Janeiro: Forense Universitária, 2005.

FUNDAÇÃO BIBLIOTECA NACIONAL. Relatório de gestão 2019. Rio de Janeiro: 2020.

Disponível em: https://www.bn.gov.br/sites/default/files/documentos/institucionais/relatoriogestao/ano-2019-6758.pdf. Acesso em: 2 out. 2020.

GOBBI, Nelson; CALAZANS, Ricardo. Mario Frias vai controlar editais e até posts de todos os órgãos da Cultura nas redes sociais. O Globo, Rio de Janeiro, 8 set. 2020. Disponível em: https://oglobo.globo.com/cultura/mario-frias-vai-controlar-editais-ate-posts-de-todos-os-orgaos-dacultura-nas-redes-sociais-24628914. Acesso em: 2 out. 2020.

GRINGS, Luciana. O leigo e a especialista: memórias da administração da Biblioteca Nacional nas décadas de 1960 e 1970. Rio de Janeiro: Fundação Biblioteca Nacional, 2019.

HOLANDA, Nestor. As eleições da Academia. Diário de Notícias, segunda seção, Rio de Janeiro, 19 jan. 1965, p.1.

O JORNAL. Rio de Janeiro: Diários Associados, 1924-1974.

JORNAL do Brasil. Rio de Janeiro: 1891-

JORNAL do Commercio. Rio de Janeiro: Diários Associados, 1959-2016.

LAUS, Lausimar. O ganha-pão querido. Diário de Notícias: suplemento literário, Rio de Janeiro, 1 maio 1966, p.6.

LIMA SOBRINHO, Barbosa. Será Deus brasileiro? Jornal do Brasil, Rio de Janeiro, 30 jun./1 jul. 1968, p.1.

LUCA, Tania Regina de. História dos, nos e por meio dos periódicos. In: PINSKY, Carla Bassanezi (Org.) Fontes históricas. São Paulo: Contexto, 2006. p.111-154.

MAGALHÃES JÚNIOR, R. O silencioso mundo da cultura. Manchete, Rio de Janeiro, n.554, p.92-97, 01 dez. 1962.

MEIRA, Mauritônio. Novo diretor da Biblioteca Nacional será Adonias Filho: nomeação já. Jornal do Brasil, Rio de Janeiro, n.39, 17 fev. 1961, p.2.

MIRANDA NETO. Exposições da biblioteca percorrerão todo o país. Jornal do Commercio, Rio de Janeiro, 26 nov. 1961, p.1. 
MOTA, Marcus. Vida/morte, morte/vida: temas e tarefas na recepção de Adonias Filho. Especiaria: cadernos de ciências humanas, Santa Cruz, v.17, n.31, p.111-146, jun./dez. 2017.

NASSIF, Luís. O café society. Folha de S. Paulo, São Paulo, 6 nov. 2005. Disponível em: https://www1.folha.uol.com.br/fsp/dinheiro/fi0611200507.htm. Acesso em: 28 set. 2020.

NEJAR, Carlos. História da literatura brasileira: da Carta de Caminha aos contemporâneos. São Paulo: Leya; Fundação Biblioteca Nacional, 2011.

A NOITE, Rio de Janeiro, 1911-1964.

SERVIÇOS da BN terão verba. Correio da Manhã, Rio de Janeiro, 03 mar. 1968, p.10.

SÜSSEKIND, Flora. Cinematógrafo de letras: literatura, técnica e modernização no Brasil.

São Paulo: Companhia das Letras, 1987.

TRIBUNA da Imprensa. Rio de Janeiro: 1949-

ÚLTIMA Hora. Rio de Janeiro: 1951-1991.

\section{BIBLIOGRAFIA CONSULTADA}

ADONIAS Filho. In: ENCICLOPÉDIA Itaú Cultural de arte e cultura brasileiras. São Paulo: Itaú Cultural, 2020. Disponível em: http://enciclopedia.itaucultural.org.br/pessoa20659/adonias-filho. Acesso em: 28 ago. 2020.

ADONIAS Filho. In: WIKIPEDIA: a enciclopédia livre. [San Francisco, CA: Wikimedia Foundation], 2020. Disponível em: http://pt.wikipedia.org/wiki/Adonias_Filho. Acesso em: 28 ago. 2020.

ADONIAS Filho: biografia. Rio de Janeiro: Academia Brasileira de Letras, [20--]. Disponível em: https://www.academia.org.br/academicos/adonias-filho/biografia. Acesso em: 28 ago. 2020.

LAPA, luri; JORDÃO, Lia. A Biblioteca Nacional na crônica da cidade: volume 1. Rio de Janeiro: Fundação Biblioteca Nacional, 2017.

SISENO Sarmento. In: WIKIPEDIA: a enciclopédia livre. [San Francisco, CA: Wikimedia Foundation], 2019. Disponível em: https://pt.wikipedia.org/wiki/Siseno_Sarmento. Acesso em: 24 set. 2020. ses 